This is the penultimate draft of an article whose final and definitive form is forthcoming in Erkenntnis

\title{
The Significance of Epistemic Blame
}

\begin{abstract}
One challenge in developing an account of the nature of epistemic blame is to explain what differentiates epistemic blame from mere negative epistemic evaluation. The challenge is to explain the difference, without invoking practices or behaviors that seem out of place in the epistemic domain. In this paper, I examine whether the most sophisticated recent account of the nature of epistemic blame - due to Jessica Brown - is up for the challenge. I argue that the account ultimately falls short, but does so in an instructive way. Drawing on the lessons learned, I put forward an alternative approach to the nature of epistemic blame. My account understands epistemic blame in terms of modifications to the intentions and expectations that comprise our “epistemic relationships" with one another. This approach has a number of attractions shared by Brown's account, but it can also explain the significance of epistemic blame.
\end{abstract}

\section{Introduction}

Epistemic evaluation is a familiar part of ordinary life. We routinely judge others to be irrational, or unjustified in holding certain beliefs. We regard others as doing something they shouldn't when they suspend judgment on a matter about which there is unequivocal evidence. Just as we have characteristic ways of responding to one another for moral failings - for example, we sometimes blame others for moral wrongdoings - it seems there are characteristic ways of responding to one another for epistemic failings. We might think that, under certain circumstances, these responses can appropriately be understood as a kind of blame response. Epistemologists increasingly discuss “epistemic blame", and deploy this notion in debates about other epistemological issues. What does it mean to epistemically blame someone? Does epistemic blame involve a kind of reproach, or the manifestation of certain reactive attitudes? Just how 
similar is epistemic blame to other, more practical, kinds of blame? Only recently has the project of developing a detailed account of the nature of epistemic blame been undertaken in earnest. ${ }^{1}$

There are a number of challenges that come with developing an account of the nature of epistemic blame. For example, it seems that an account should be able to explain the possibility of private epistemic blame, as well as the possibility of epistemically blaming agents in the distant past. In this paper, I orient discussion primarily around one central challenge. As with moral blame, a central challenge in developing an account of epistemic blame is explaining what it is about epistemic blame that goes beyond mere negative epistemic evaluation. It is one thing for me to judge that you have done something epistemically remiss, or to judge that you have violated an epistemic norm. It is another for me to blame you for violating that norm. Blamers are engaged by their evaluations in a way that negative evaluation alone does not imply. This idea goes hand in hand with some familiar features of blame. For instance, it seems one must meet certain conditions of standing to appropriately blame someone. ${ }^{2}$ Meeting such conditions seems less important, if important at all, when merely negatively evaluating others. The appropriateness of blaming someone also seems tied to questions about what is under their control, and what they are in a position to know, in a way that merely negatively evaluating someone does not. These differences highlight a characteristic significance that blame has.

A number of explanations of the significance of moral blame do not seem fitting as models for epistemic blame. For example, according to a well-known account, what sets moral blame apart from negative moral evaluation is that moral blame necessarily involves negative emotional responses, such as indignation and resentment (Strawson 1962; Wallace 1994, 2011; Wolf 2011). This approach has been criticized in recent years, mainly because it seems that we can morally blame people in a cool fashion, without feeling indignation or resentment (Smith 2013; Fricker 2016). ${ }^{3}$ I might blame you for forgetting my birthday, but fail to feel indignation or resentment because you have forgotten so many times it has become routine. Such a model is perhaps even more problematic in the epistemic domain. People may be the appropriate targets of 
epistemic blame even though they are not the appropriate targets of anything as fiery as indignation or resentment. ${ }^{4}$

A key challenge in developing an account of epistemic blame is explaining how it goes beyond mere negative evaluation, but doing so in a way that allows for the possibility of cool forms of epistemic blame, and otherwise fits within a natural understanding of our actual epistemic practices. The most recent account of the nature of epistemic blame seems wellpositioned to do just this. Drawing on George Sher's influential work on moral blame (2006), Jessica Brown (2020) has developed an account of epistemic blame in terms of a characteristic set of dispositions unified by a certain belief-desire pair. Brown argues that the account has a number of attractive features, including the ability to explain private epistemic blame, and to capture the wide variety of manifestations that epistemic blame can take.

The role of desire in the account underpins its promise in the present context. Perhaps epistemic blame's characteristic significance can be explained in terms of a certain connection to motivation that is lacking in cases of mere negative evaluation. I may judge that you have violated some epistemic norm without being moved to do anything. But when I blame you for violating that norm, this goes beyond mere negative evaluation because I am thereby motivated in certain ways.

While Brown's account might seem well-positioned to meet the challenge of explaining blame's significance, in this paper I argue that it ultimately falls short. However, I argue that it falls short in an instructive way. This leads me to put forward an alternative approach to epistemic blame..$^{5}$ My alternative approach has a number of attractions shared by Brown's account, but it can also explain the significance of epistemic blame. On my view, we should articulate the motivational component of epistemic blame in terms of certain modifications to the intentions and expectations that comprise our "epistemic relationships" with one another. In slogan form, these are intentions and expectations we have towards one another that are oriented towards our epistemic agency in different ways, whether towards the cultivation, or the utilization 
of our epistemic agency. I argue that this allows us to explain what epistemic blame is beyond negative epistemic evaluation, without invoking attitudes or practices that seem out of place in the epistemic domain.

Section 2 presents Brown's Sher-based account, and explains my worries about it. Section 3 puts forward the relationship-based account of epistemic blame. Section 4 advertises the main advantages of the relationship-based account. Section 5 considers objections and replies. Section 6 concludes.

\section{Brown on Epistemic Blame}

According to Brown, Sher's (2006) theory of moral blame provides a helpful framework for understanding the nature of epistemic blame. Sher argues that moral blame consists in a characteristic set of dispositions to feel and behave, unified by a particular belief-desire pair. The relevant belief is that the person blamed has "acted badly", and the relevant desire is that the person blamed not have acted badly. The notion of a bad act is a technical one for Sher. He does not merely mean the violation of some moral norm. After all, people can blamelessly do what is morally impermissible. They can also do morally permissible things in blameworthy ways. By "acting badly", Sher means acting in a blameworthy way. The sorts of dispositions Sher has in mind are just those we ordinarily associate with blame. For example, we ordinarily associate blame with negative emotional responses, reproach, and apology (if one blames oneself). According to Sher, it is not enough to theorize blame merely as the set of dispositions ordinarily associated with blame, as this leaves us without any understanding of what they have in common.

Relatedly, it leaves unexplained why we have a single concept of blame that we regard as morally important. Thus, his account includes the claim that what unifies these characteristic dispositions is that they are caused by moral blame's characteristic belief-desire pair. The basic idea is that the negative emotions or other dispositions typical of blame are a specific case of the more general phenomenon of how one feels when one's desires are frustrated. Indeed, the dispositions 
characteristic of blame can be understood as manifestations of the unsatisfied desire that the relevant norm not be culpably violated.

Brown imports the structure of this idea straightforwardly into the epistemic domain. All that needs modifying are the characteristic dispositions to feel and behave, along with the contents of the belief-desire pair. According to Brown, dispositions to feel and behave typically associated with epistemic blame include anger and publicly expressed rebuke, as well as attempts to get the target of blame to appreciate the reasons they had previously failed to appreciate. The content of the belief-desire pair unifying such dispositions is, of course, epistemic in nature. That is to say, the relevant belief involved in epistemic blame is that the target of blame has "believed badly" - which Brown uses as shorthand for the idea that the target has culpably flouted some epistemic norm (she remains neutral on what the correct epistemic norm(s) is/are). ${ }^{67}$ The relevant desire is that the target not have believed badly, or otherwise culpably flouted the relevant epistemic norm. The dispositions characteristic of epistemic blame can be understood as manifestations of the unsatisfied desire that the relevant epistemic norm not be culpably violated.

This is a promising way of explaining how epistemic blame goes beyond mere negative epistemic evaluation. Again, the idea would be that epistemic blame's characteristic significance can be explained in terms of a certain connection to motivation that is lacking in cases of mere negative evaluation. One may judge that you have violated some epistemic norm without being moved to do anything. But when one person blames another for violating a norm, this goes beyond mere negative evaluation because they are thereby motivated in certain ways.

Must epistemic blame be accompanied by a desire that the target of blame not have believed badly? One might be suspicious of this idea for the reason that ordinary people seem to lack a general desire for truth and knowledge. Cases of trivial truths and trivial knowledge abound. Sometimes people seem to desire the absence of true belief and knowledge (consider reactions to movie spoilers (Kelly 2003, 20)). If that is so, why must it be the case that, when epistemically blaming someone, and thereby believing that they have believed badly, we must 
also desire that this is not the case? What if the target of epistemic blame believed badly and thereby failed to form a true belief about the number of " 8 "s on page 406 of the Yellow Pages? Perhaps the account does not fit with our actual epistemic practices after all.

Brown responds that it does not matter whether people have a general desire for truth and knowledge. All she maintains is that in each case of epistemic blame, the blamer has a desire that the target of blame not have believed badly. In all cases of epistemic blame, the blamer desires that this person in this case not have believed badly. One might be tempted to challenge this claim, too, by arguing that there can be cases of epistemic blame that do not involve a desire that some epistemic norm has not been violated. ${ }^{8}$ But Brown has room to maneuver here. According to Brown, even if there seem to be cases of epistemic blame without the relevant desire, this may simply be due to the fact that the relevant desires in such cases are either very weak, or overridden by other desires (or both) (Brown 2020, 10). Appealing to differences in strength of desire can also help explain the variable strength of epistemic blame. Stronger expressions of epistemic blame may correspond to stronger desires that the relevant epistemic norm has not been violated. According to Brown, the fact that epistemic blame seems less common and less strong than moral blame can be explained by noting that the desire that people not believe badly, in token situations, is usually less strong (thus more easily overridden) than in cases of morally wrong action.

I agree that some sort of motivational component is necessary for epistemic blame. However, I'm not convinced that understanding the motivational component as a desire that the target of epistemic blame not have believed badly is the best way of pursuing this more general idea. To start, a worry that Angela Smith has presented against Sher's original account also seems problematic for Brown. ${ }^{9}$ Consider a mother who judges that her son has done something horribly wrong, and is blameworthy for doing so. She desires very much that her son not have done this horrible thing; she knows that his implication in the wrongdoing will make his life more difficult. The mother has the belief-desire pair at the heart of Sher's account. She believes her son 
blameworthy, and desires that he not have culpably violated the relevant moral norms. However, imagine that she falls short of manifesting any of the dispositions characteristically associated with blame. Perhaps she simply feels a great deal of remorse and sadness about the whole thing. These are not dispositions characteristically associated with blame. Crucially, it seems entirely natural to imagine the mother manifesting these attitudes towards her son as a result of having Sher's belief-desire pair. The case is not a far-flung possibility. ${ }^{10}$ For this reason, it seems there is work to do in order to show that the dispositions characteristic of moral blame are the sorts of things we should expect to manifest when the desire component of the belief-desire pair at the heart of the Sher's framework is frustrated. Why is it the case that sometimes dispositions manifest which have seemingly not much to do with blame, and at other times, dispositions characteristic of blame do manifest? What makes the difference between these sorts of cases? ${ }^{11}$

A parallel point can be made in the epistemic domain. A mother believes that her son is epistemically blameworthy for failing to study carefully for an upcoming exam. She also desires that her son not have violated the epistemic norms he has violated; she knows that this epistemic failure is going to make his life more difficult. ${ }^{12}$ Despite having the belief-desire pair at the heart of Brown's account, the mother falls short of manifesting any of the dispositions characteristically associated with epistemic blame. She simply feels a certain degree of regret or sadness over the matter. ${ }^{13}$ Once again, it seems entirely natural to imagine that the mother manifests these attitudes towards her son as a result of having Brown's belief-desire pair. The case is not unusual. So, it seems there is work to do in order to show that the dispositions characteristic of epistemic blame are the sorts of things we should expect to manifest when the desire component of the belief-desire pair at the heart of Brown's framework is frustrated. ${ }^{14}$ Indeed, at this point, it is fair to wonder whether something more might be involved in cases in which the dispositions characteristic of epistemic blame are present, something over and above a belief that the target of blame has believed badly, and the desire that they not have believed 
badly. Perhaps some further component is required to explain the difference between the cases I have in mind..$^{15}$

Here is another way of explaining why Sher's belief-desire pair seems inadequate to the task at hand. Note first that, despite the fact that Sher appeals to a belief-desire pair to explain what unifies our blame responses, the desire component is arguably what's doing the heavy lifting. Recall that the belief in this belief-desire pair is the belief that the target of blame has "acted badly". Recall that, by this, Sher does not simply mean that the target of blame has violated some moral norm. Again, people can blamelessly do what is morally impermissible. They can also do morally permissible things in blameworthy ways. By "acting badly", Sher means acting in a blameworthy way. But then, as Sher has pointed out in the context of developing his own theory, the account must appeal to the desire condition in order to have anything to say about what the belief condition amounts to - that is, in order to have anything to say about what it is that a blamer believes a person is worthy of when one blames them (Sher $2007,75)$. This, in my view, is why the desire component is doing the heavy lifting in Sher's account (as well as Brown's). Appropriate targets of blame are worthy of being on the receiving end of the dispositions the blamer manifests as a result of desiring that the blamee not have acted or believed badly.

Second, it seems to me that when people manifest the dispositions characteristic of blame, it is not simply because they want it to be the case that someone hadn't acted badly. Something else seems to be involved (I will examine some options shortly). Consider how people typically react when they hear about some natural disaster, such as a hurricane striking a populated center, or a wildfire destroying peoples' homes. When we respond to such events, we typically want it to be the case that these horrible things not have happened. And yet, we do not direct genuine blame responses towards avalanches or wildfires, no matter how much destruction they may have caused. Of course, the content of one's desire that a natural disaster not have occurred is different from the content of one's desire that a person not have acted badly. Perhaps 
people manifest the dispositions characteristic of blame only when, and precisely because, they have a desire with a very specific sort of content. But it is not clear that the content of the desire in the Sher-based framework can do the work needed here. Indeed, this is what the mother-son case seems to illustrate. Again, there seem to be very natural sorts of cases where an agent can desire that someone not have acted badly and yet fail to manifest any of the dispositions characteristic of blame.

Returning to Brown's account, a structurally similar point can be made in the epistemic case. Consider how we might respond when we discover that, despite appearances to the contrary, some significant set of our beliefs are unjustified and false; there is much less knowledge in the epistemic community than we had previously thought. One would typically desire that such an unfortunate state of affairs not have occurred. But it seems clear that our dispositions to react when this desire is frustrated will not amount to epistemic blame responses. Of course, the content of one's desire that an epistemic mishap not have occurred is different from the content of one's desire that a person not have believed badly. But, as in the moral case, it remains unclear to me that this point alone can do the work needed. This is what the epistemic analogue of the mother-son case seems to effectively illustrate. Again, there seem to be very natural sorts of cases where an agent can desire that someone not have believed badly and yet fail to manifest dispositions characteristic of epistemic blame.

It is not clear that Brown's desire condition can make sense of the idea that epistemic blame is something over and above mere negative evaluation. Following Smith, I take this to suggest that the motivational component of epistemic blame involves something other than, or in addition to, a desire that the target of blame not have believed badly. Smith's own suggestion is that, in the moral case, "we understand the distinctive motivational element implicit in all instances of moral blame as a disposition to protest conduct that we regard as wrongful or disrespectful to ourselves or others" (2013, 36 [my emphasis]). I am not optimistic that such an account can be extended to the epistemic domain. Recall, the central challenge is to explain what 
epistemic blame is beyond mere negative evaluation, while being able to account for our actual epistemic practices. Modelling all cases of epistemic blame on the protest of wrongful or disrespectful behavior does not seem promising in this regard, because the notion of protest to conduct that is wrongful and disrespectful does not seem particularly promising as a way of understanding our responses to epistemic failings.

Yet Smith's worry about the Sher-based framework contains an insight. It is worth thinking about whether the insight can be captured in other ways. One approach that seems particularly promising, is to look at the modifications we make to intentions and expectations constitutive of our relationships with one another, in ways made fitting by perceived impairments to those relationships. I turn now to articulate the basic idea behind this alternative proposal. In Section 4, I will explain its advantages over Brown's account of epistemic blame.

\section{A Relationship-Based Account of Epistemic Blame}

In my view, epistemic blame is a kind of relationship modification. ${ }^{16}$ My account is inspired by a family of views that put relationships at the heart of our understanding of moral blame (Strawson 1962; Scanlon 2008;2013; Wallace 2013). Perhaps the most prominent of these views, and the one that utilizes the concept of a relationship most directly and significantly, is T.M. Scanlon's account.

I follow Scanlon in using the term "relationship" in a somewhat technical sense. According to Scanlon, relationships are constituted by certain intentions, expectations, and attitudes people have concerning how to act and feel towards one another. ${ }^{17}$ We can distinguish between relationships as normative ideals-idealized sets of intentions, expectations, and attitudes that would be constitutive of a good relationship, whether friendships, romantic relationships, or something else — and actual token relationships; the latter are instances of actual relationships which will approximate to a better or worse degree the relevant normative ideal. 
According to this framework, a judgment of blameworthiness is a judgment that someone with whom you stand in some relationship has intentions, expectations, or attitudes that in some way fall short of the normative ideal of that relationship (such a judgment need not be explicitly recognized as such by the judger). A blame response consists in a modification to the intentions, expectations, and attitudes you have towards that person, in a way made fitting by the judgment that they are blameworthy. This combination of judgments, and modifications to intentions and expectations as a result, is what a blame response consists in.

Importantly, reactive attitudes like indignation and resentment — attitudes that figure prominently in other accounts of moral blame (Wallace 1994, 2013; Wolf 2011) - are allowed a role in in this framework. However, they are not central. Forming certain reactive attitudes under certain circumstances may constitute one way of modifying our relationships with one another. But relationship modification can be done in many ways.

This basic structure can be extended in an illuminating way to the epistemic domain. In my view, judgments of epistemic blameworthiness are judgments that someone has fallen short of an ideal set of intentions and expectations that comprise one's "epistemic relationship" with that person. Epistemic blame-responses consist in actual modifications to those intentions and expectations, in a way made fitting by this judgment. In slogan form, an epistemic relationship is a set of intentions, expectations, and attitudes people have towards one another that are oriented towards their epistemic agency in different ways. Sometimes they are oriented towards cultivating epistemic agency; other times, they are oriented towards utilizing it in more or less specialized ways. ${ }^{18}$ There may be a number of different kinds of epistemic relationship. The following is a sketch of a very basic kind, which I call the "general epistemic relationship" (in Section 4 I spell out details of a more specific kind of epistemic relationship).

Members of an epistemic community rely on one another for such basic things as finding out where the nearest gas station is, or whether a meeting has been rescheduled. Under certain conditions, at least, we also often have a degree of confidence in one another, in the sense that, 
unless we have good reason not to, we generally expect (in both a normative and predictive sense of "expect" (Goldberg 2020)) the assertions of others to be true. In my view, members of an epistemic community stand in a relationship of mutual epistemic trust. Trusting someone entails, among other things, that you do not think they are out to deceive you or otherwise present you with purposefully misleading information. Epistemically trusting someone entails only that you have confidence that they are a reliable source of information - that believing what they say is a way of arriving at a favourable ratio of true to false beliefs, or knowledge, or understanding, etc.- - and that you are willing to rely on them as such (McCraw 2015). When all goes well — that is to say, according to the normative ideal of this relationship of mutual epistemic trust - each member intends to epistemically trust another unless one has good reason not to. And each member expects others to actually be epistemically trustworthy in this way, as well as that they will do the same of them. ${ }^{19}$

Details about the nature of this relationship will need filling in. Who exactly counts as a member of the epistemic community? What counts as a good reason to suspend a presumption of epistemic trust? How finely grained should our presumptions of epistemic trust be individuated? People can be highly reliable on one subject matter, while being unreliable on another. Answers to these questions will go hand in hand with our understanding of such foundational issues in epistemology as the nature of defeat, and the nature of testimonial justification. I aim to remain as neutral as possible on those issues. Even at a very skeletal level, we can use the general epistemic relationship to make sense of a wide range of examples.

Epistemologists typically use cases of dogmatism (Brown 2020, 11), wishful thinking (Nottelmann 2007, 75; Russel 2001, 40), hasty reasoning (McHugh 2012, 66), and certain kinds of biased cognition (see Bartolotti and Miyazono 2015) as examples of epistemic failings for which people can be appropriate targets of epistemic blame. What these failings have in common is that they are examples of intellectual conduct that tends to give others good reason to suspend their presumption of epistemic trust in would-be targets of epistemic blame, at least within some 
restricted domain, or on some specific matter. A core idea of the relationship-based account of epistemic blame, then, is that one party to the general epistemic relationship can appropriately epistemically blame another for conducting their intellectual lives in a way that gives one a good reason to suspend their presumption of epistemic trust in that person, at least within some restricted domain, or on some specific matter.

This is an upshot of the fact that such intellectual conduct is constitutive of an impairment of the general epistemic relationship; it is one way of falling short of the normative ideal. By dogmatically holding a belief despite having excellent evidence to the contrary, for example, depending on the details of the situation, an agent may impair the general epistemic relationship in the sense that they fall short of at least one expectation that is constitutive of it, namely the expectation that others will actually be epistemically trustworthy, at least within some restricted domain, or on some specific matter.

On my account, one's modification to this expectation and corresponding intentions- for example, revising one's intention to epistemically trust the word of another person on a subject matter they seem to be prone to think dogmatically about — in a way made fitting by the judgment that one's epistemic relationship has been impaired, just is what it means to epistemically blame that person for their epistemic failing $\cdot{ }^{20}$ This does not need to be a very weighty or strong kind of blame. All of this can happen in subtle ways. But that is exactly as it should be. When we epistemically blame someone for dogmatically believing something in the face of excellent evidence to the contrary, in many circumstances it need not be a particularly heated kind of blame.

I will discuss a number of potential objections to the relationship-based framework in Section 5. The following is one objection I would like to address before moving on, since doing so will help avoid a potential misunderstanding of the account. Someone might object that the account classifies too many cases as cases of epistemic blame. For example, when I stop expecting someone to know something, simply because I come to realize they aren't as 
knowledgeable as I thought they were, do I thereby epistemically blame them? Doesn't the account imply that I do $?^{21}$ Note that the account requires that an adjustment of one's epistemic expectations be the result of a judgment: namely, the judgment that the target of blame has done something to impair the general epistemic relationship. Of course, as I have pointed out above, the blamer need not make this judgment under this description. Indeed, arguably nobody doesafter all, the general epistemic relationship is a technical notion. It aims to capture what's theoretically interesting about the sorts of judgments that people do make when they pretheoretically seem to count as epistemically blaming someone. For example, epistemic blamers tend to judge that someone has been intellectually irresponsible, or intellectually vicious, or reckless, or just plain "stupid". Those are the sorts of things I take the notion of a judgment of general epistemic relationship impairment to unify. Only when an agent modifies their epistemic expectations in a way made fitting by this sort of judgment do they count as epistemically blaming others. So, the above case does not show that the account overgeneralizes.

\section{Advantages of the Relationship-Based Account}

For those sympathetic to the idea that desires about norm violation are not necessary components of epistemic blame, the relationship-based account will be attractive for the reason that it remains silent on whether a desire about norm violation is necessary for epistemic blame. Modifications to epistemic relationships do not necessarily require the manifestation of any such desire (though of course they might).

But I have agreed with Brown that some kind of motivational component is necessary for epistemic blame. Instead of frustrated desires about bad believing, my account puts the notion of relationship-modification at center stage. This is attractive because it enables a way of capturing how epistemic blame goes beyond mere negative evaluation, without invoking attitudes or practices that seem out of place in the epistemic domain. How so? For a start, modifying one's relationship with another person is more significant than simply negatively evaluating them. It is 
one thing for me to judge that you have done something epistemically remiss, to assign you a bad epistemic grade. It is another for me to modify the intentions and expectations that comprise part of a relationship I stand in with you in response to this shortcoming. Relationships are significant things. Of course, some relationships are more significant than others. My marriage is more significant to me than my relationship with my car mechanic. There may be different kinds of epistemic relationship, and some of them may have greater significance than others. This squares with the idea that some instances of epistemic blame are stronger, or different in kind, than others (I discuss the connection between different kinds of relationship and different kinds of blame below).

While relationship modification underpins the idea that epistemic blame is more than mere negative epistemic evaluation, it is also something that fits nicely within the epistemic domain. To take the central example I used when filling out the general epistemic relationship, modifying one's intention to epistemically trust the word of another person on a subject matter they seem to be prone to think dogmatically about, is something people do all the time. In contrast with alternative possible approaches to epistemic blame-for example, ones that might take moral emotions like indignation and resentment as a model, or Smith's idea of moral protest as a model - the relationship-based account can articulate the motivational component distinctive of epistemic blame in a way that is tailor made for the epistemic domain. This is because it is relatively easy to import the idea of relationship-modification to the epistemic domain. We simply have to focus on modifications to people's intentions and expectations that are oriented towards the cultivation or utilization of epistemic agency.

Modifications to our epistemic relationships have the right kind of significance, without fitting awkwardly within a pre-theoretical understanding of our actual epistemic practices. An advantage of the relationship-based account is that, by linking the motivational component of epistemic blame to relationship-modification, it seems to tell us something deeper about the nature of epistemic blame than Brown's appeal to frustrated desires. 
Desires about bad believing nevertheless seem to play a role in many instances of epistemic blame. If an account of epistemic blame can explain why such desires seem present in some cases of epistemic blame, but not others, that would be a strong mark in favour of the account. The relationship-based account is well positioned in this regard. Some (perhaps many) cases of epistemic blame involve a desire (or other emotional responses) because we (generally) want to be able to have well-functioning epistemic relationships with each other. Epistemic relationships are useful things. But the relationship-based account can also explain why some cases of epistemic blame may intuitively lack desire (for example, the case in endnote 8). In such cases, the blamer may all things considered be happy to have their epistemic relationship with the target of blame impaired in the relevant way (i.e. they may lack a desire to not have it impaired). This is not to say that the blamer thereby opts out of that relationship, or that they were never in it to begin with. It is only to say that, in such cases, they lack the desire that their flawed epistemic relationship be any different than it is.

The relationship-based account also has resources available to explain the variable strength of epistemic blame. The fact that each of us partakes in many different kinds of relationship can partly explain the differences we see in strengths of token instances of epistemic blame. Such differences at least partly correspond to differences in the intentions and expectations that define different epistemic relationships. Perceived failures to live up to such ideals makes different sorts of responses fitting. For example, a scientist might be open to a stronger epistemic blame-response (involving more emotion, or more consequential changes in one's intentions) than a layperson for failing to conform their beliefs to the evidence, because of differences in what this says about their attitudes toward the respective parties to the epistemic relationships the scientist and layperson are in. When a scientist is lazy and misses some important bit of evidence, this may say something about the way they view their role in the scientific community, and perhaps the role of that community in the broader epistemic 
community. It may say something about them that seems particularly epistemically bad. So, a strong epistemic blame-response can be fitting.

Another advantage of the account is its ability to provide a nuanced explanation of a wide variety of kinds of epistemic blame. Consider the following example from Lindsay Rettler: "As a philosophy professor who regularly teaches critical thinking and logic courses, Brette finds herself indignant at the unreasonable beliefs of her incoming freshman class this fall. In particular, Brette blames her student Seth for believing that his chances of meeting a celebrity are high just because he's never met one until now" (Rettler 2017, 4). It is plausible that the nature and norms of epistemic blame make room for nuances in certain kinds of cases. Brett is in a unique position vis-à-vis her students-it is her job to do what she can to bring it about that they learn some range of material. Perhaps as a result, when her students violate epistemic norms and Brett epistemically blames them for it, she does so in a way that is unique to the relationship between teachers and students.

The relationship-based account of epistemic blame is well-positioned to do justice to this idea. We can start by spelling out the intentions and expectations of the normative ideal of what might be called the "teacher-student relationship". When all goes well, teachers intend to do what they can to bring it about that their students are in a position to learn the relevant material within a certain timeframe. And they expect their students to do what they can to be in a position to learn the relevant material within that timeframe. When all goes well, students themselves have intentions and expectations that inversely mirror those of the teacher, such that they expect their teacher to do what they can to bring it about that the students are in a position to learn the relevant material within a certain timeframe, and they intend to do what they can to be in a position to learn the relevant material within that timeframe. These broad descriptions of intentions and expectations will entail more specific intentions and expectations, depending on contextual factors, and details about the individuals involved. Having such basic intentions and expectations is arguably central to being a good teacher. More peripherally, there are also plausibly certain 
supererogatory dimensions to this relationship, such that a teacher will, ideally, intend to feel a degree of enthusiasm for their students when they meet certain benchmarks in the process of learning.

Both Brette and the students are engaged in the process of living up to (or failing to live up to) the intentions and expectations specified by the normative ideal of teacher-student epistemic relationship. By going in for such an obviously fallacious piece of reasoning, we might say that Seth fails to live up to the normative ideal of the teacher-student relationship. More specifically, he fails to understand material of a certain degree of difficulty within a certain timeframe. Brette's blaming of Seth may consist simply in a judgment that Seth has done something to impair that relationship (however slightly), and a modification to her intentions and expectations as a result. Brette might modify her expectation that Seth will understand material of a certain degree of difficulty within a certain time-frame. She might even slightly modify her intention to feel a certain degree enthusiasm towards Seth when he understands the relevant material (perhaps accompanied by a mild form of indignation, as Rettler describes the case). This is one explanation of what this form of epistemic blame consists in. Brette is in a position to epistemically blame Seth, in the unique way that she is positioned to, in part because of the role his epistemic failing plays in their epistemic relationship. ${ }^{22}$

Meanwhile, it is not quite clear how an account that puts frustrated desires about norm violation at center stage is really in a position to do anything as nuanced as this. If all cases of epistemic blame are essentially manifestations of a disposition to desire that an epistemic norm not be culpably violated, how exactly can we explain the difference between what a teacher does when she epistemically blames her student, and what a scientist does when he epistemically blames his colleague? Is this really just a matter of differences in strength of the desire that an epistemic norm not have been violated? The finer-grained properties with which the relationshipbased account underpins token instances of epistemic blame enables a more nuanced explanation of this difference. There are differences in the contents of the intentions and expectations 
specified by the normative ideals of the teacher-student relationship in comparison with the general epistemic relationship. Instances of epistemic blame in each of these kinds of relationship will thus naturally reflect these differences. This is closely related to the account's ability to explain differences in strength of epistemic blame. But rather than accounting for differences in kinds of blame in terms of differences in relative strength, we account for relative strength in terms of differences in the contents of the intentions and expectations that are being modified as a fitting response to relationship impairment. This feature will be important when it comes to addressing objection 5.6 below.

\section{Objections and Replies}

Relationship-based approaches to blame are not without critics. In this final section, I address some of the more pressing worries.

\subsection{Taking the Blame out of Blame}

R.J. Wallace (2011) and Susan Wolf (2011) have argued in different ways that relationship-based approaches - in particular, T.M. Scanlon's account of blame- "leaves the blame out of blame" (Wallace 2011). While both Scanlon and myself have advertised as a feature of the relationshipbased approach that it can accommodate the coolness of certain kinds of blame, Wallace and Wolf argue that it goes too far in this regard. According to Wallace, reactive attitudes such as indignation and resentment simply are essential to what it really means to blame someone. The

fact that relationship-based approaches do not give them a central role is a defect of the approach, according to Wallace and Wolf. Ultimately, I do not want to take a stand on whether this is true

of moral blame. But I will emphasize again that, in my view, this point reveals one reason why an extension of relationship-based approaches to blame to the epistemic domain seems particularly promising. As I have said, while reactive attitudes such as indignation and resentment may be integral to moral blame, they do not seem integral to epistemic blame. ${ }^{23}$ 


\subsection{Blame Without Relationship Modification}

It seems there can be cases in which a person intuitively blames someone, but does not modify their intentions and expectations towards that person in any way. For example, a husband fails to bring his partner anniversary flowers for the $7^{\text {th }}$ year in a row; his partner might blame him for this, but not make any modifications to his intentions and expectations-it's just too familiar by now. What can the relationship-based account say about such cases?

First, perhaps even in a case like this, one may modify their intentions and expectations ever so slightly, in a way made fitting by the judgment that the relationship falls short of some normative ideal. Given the contextual features of the case, even very subtle adjustments may provide a plausible way of understanding what someone's blame-response consists in. But we can also simply make a minor adjustment to the way I presented the relationship-based account. In addition to focusing on modifications to intentions and expectations, we can add the plausible idea that sometimes our existing intentions and expectations simply become more recalcitrant, in response to judgments of relationship-impairment. Under certain circumstances (such as those of the husband), perhaps this too can be central to a blame response. It is interesting to consider the mechanisms by which our intentions and expectations might become more recalcitrant in these scenarios. Perhaps they become more recalcitrant through a kind of reaffirmation (whether done consciously or not), in the sense that we modify certain higher-order intentions and expectations regarding existing first-order intentions and expectations. ${ }^{24}$ In any case, it may be true that the man blames his husband in the above example without making any modifications to his (firstorder) intentions and expectations. But it's plausible that when the man judges his husband blameworthy, he nevertheless reaffirms, or in some way maintains the intentions and expectations he originally formed in response to the impairment a number of years ago.

Lastly, if the husband really does not modify his intentions and expectations in any way, nor do his intentions and expectations become more recalcitrant, then I simply find it implausible 
to say that, on the moment of the $7^{\text {th }}$ wedding anniversary, anything takes place that constitutes a new blame response over and above some existing stance he already takes toward his husband. ${ }^{25}$

\subsection{Relationship Modification Without Blame}

Angela Smith $(2013,137)$ presents the example of a mother intending to care for and appreciate her son even more upon learning of a particular crime he has committed. She has used this case to argue that Scanlon, in particular, is forced classify certain kinds of relationship modification as instances of blame that intuitively are not instances of blame. The case seems equally pressing for my own account.

In response to this sort of worry, it is important to remember that there is a central role for judgments of blameworthiness in the relationship-based account, as well as the claim that, in order to count as blame responses, modifications to one's relationship with another person must be ones that are made fitting by that judgment. The mother does not seem to meet the latter condition. That is, it doesn't seem right to say that her response is one that is made fitting by the judgment that her son is blameworthy, at least not from the point of view of morality. Indeed, we might say that her feelings of partiality towards her son are, in some sense, getting in the way of her ability to blame her son.

Moreover, the account does not merely maintain that modifications to one's expectations and intentions should be made fitting by a judgment that $\mathrm{X}$ is blameworthy; rather it maintains that these modifications should be made fitting by a judgment that $\mathrm{X}$ has done something to impair one 's relationship with them. In Smith's mother-son case, the mother simply judges that the son is blameworthy, presumably in the sense that he has done something to impair some other relationship, as to opposed to their own parent-child relationship. If so, it is not clear that her reaction need be classified as a blame response according to the account. 


\subsection{On Fittingness}

Still, it seems fair to request an explanation of which modifications to our relationships count as fitting responses to judgments of relationship impairment, and why that is the case. Some might argue that this talk of "fittingness" is rather vague, and potentially ad hoc.

The account ultimately relies on a shared grasp of the sorts of things we typically associate with blame and relationship impairment. In this regard, it is no different from Brown's appeal to Sher's account of moral blame. As we have seen, according to Sher, blame is a characteristic set of dispositions to feel and behave. The sorts of dispositions Sher has in mind are just those we "ordinarily associate with blame" (Sher 2006, 93-114). Like Sher, I am not in the business of giving a reductive analysis of blame. The primary contributions of both these fameworks is their explanations of what unifies a diverse range of phenomena in our practice of responding to one another for normative failings. In Sher's case, it is a belief-desire pair. In my own, it is the modification of intentions and expectations in response to the judgment that one's relationship has been impaired.

We can also embrace a somewhat revisionary approach to the concept of blame (Scanlon 2008, 211). Perhaps some things that get counted as blame on our account do not seem intuitively quite like blame; this may simply be a cost proponents of the relationship-based framework should be willing to take on, in light of theoretical advantages the account has otherwise. In such cases, it is open to for one to admit that perhaps we don't think of them quite fully as blameresponses, but argue that we should. Scanlon himself has done much to highlight the theoretical advantages of his own relationship-based approach to blame (he explores issues such as moral luck, and the relationship between blame and control) (Scanlon 2008, 123-213). This paper is in part an exploration of a further theoretical advantage, namely the applicability of some of its central ideas to the epistemic domain. 


\subsection{Self-Blame}

It may seem unclear how an account of blame that grounds our understanding of blame in our relationships with one another can account for the intuitive idea that that one can blame oneself for an action or attitude. To take self-blame on board, we need to countenance the idea one can have a relationship with oneself, and that there are ways we can impair this relationship, and modify it in response to judgments of impairment. I suggest that one does have a relationship with oneself, perhaps even in the ordinary sense of that term. After all, we do tend to rely on ourselves, believe in ourselves, know ourselves, hate ourselves, and love ourselves. These are all things that arguably figure essentially in our relationships with others, things that make those relationships the sorts of things that they are.

This claim is even more plausible when we recall the technical sense of 'relationship' that I am working with. In the framework, relationships are, roughly speaking, just sets of intentions and expectations people have concerning how to act and feel towards one another. To accommodate the idea of a relationship with oneself, we can allow that there are certain intentions and expectations that one can have towards oneself-intentions and expectations concerning how one will act toward oneself, and concerning the feelings one has for oneself. This is a familiar idea. When one blames oneself, on this picture, one judges that one falls short of some normative ideal (one let oneself down, say) and modifies one's understanding of one's relationship with oneself in a way made fitting by that judgment. Perhaps one places less trust in one's ability to follow through in the future, and perhaps this is accompanied by guilt or anger, etc.

\subsection{Blaming the Dead and the Distant}

Some have objected to the relationship-based framework by pointing out that it seems we can appropriately blame people with whom we do not stand in any personal sort of relationship (Sher 2013, 50-55; Wallace 2011, 360). Opponents of the framework have taken this as evidence that the notion of a relationship is not doing any real theoretical work for the account. ${ }^{26}$ Consider 
reading in the Sunday paper about a gruesome series of murders, and that the courts have found person $\mathrm{X}$ guilty of committing them. You might blame person $\mathrm{X}$ for the gruesome murders, even though you only just heard about the existence of person X. Or consider learning about the atrocities committed by dictator Y in distant country Z. You don't stand in any obvious sort of relationship with dictator Y, but you might blame them for the atrocities. Relatedly, Sher has argued that we can appropriately blame dead people in the distant past (Sher 2013). Call these cases of "impersonal blame". How can the relationship-based account for them?

There are two main things to say in response. The first is to emphasize the importance of the distinction between blaming and judging blameworthy. When reacting to these sorts of cases, one must not mistake the intuitiveness of the idea that the Sunday morning paper reader of course judges the murderer blameworthy, with the idea that the Sunday morning paper reader actually blames the murderer. I find this especially salient when thinking about culpable dead people from the distant past, such as Leopold II. Some may find it more intuitive to say that they judge such people blameworthy (perhaps extremely so) than that they actively blame them for their horrible deeds.

Still, for those who disagree, a second point can be made. Even if it is true that we sometimes appropriately blame the distant and the dead, this does not show that the notion of a relationship is doing no theoretical work for the account. One way to see this is to consider the following. Note that the nature of our responses in cases of impersonal blame intuitively differ in character in comparison with the sorts of responses we have to impairments to our personal relationships. For example, whatever the Sunday morning paper reader's response amounts to, intuitively it will have a different character from the sort of response they would have towards a good friend for betraying an important secret. It is also plausible that whatever my response to dictator $\mathrm{Y}$ in distant country $\mathrm{Z}$ amounts to, it will be very different in character in comparison with the response of someone who is currently suffering under the reign of that dictator. If we can appropriately blame perfect strangers for wrongdoings — even ones as grave as murder — arguably 
we do so in a somewhat more detached and abstract kind of way. Meanwhile, when we blame our good friends for betraying our trust, for example, this typically consists in, or is accompanied by, much more specific sorts of emotions, behaviors, and attitudes - things that have a more direct connection to the lived reality of our daily lives. The notion of a relationship does important theoretical work for the relationship-based framework insofar as it can help explain the difference in character between these different kinds of responses. For example, we can say that impersonal blame consists in a modification to attitudes that comprise some very thin notion of a relationship one stands in with the blamee; for example, we might say that all members of the moral community stand in this comparatively thin relationship insofar as they are fellow rational beings capable of showing concern for the moral justifiability of their actions and attitudes (Scanlon calls this the "moral relationship" (2008, 39-40)). Meanwhile, blame within personal relationships involves modifications to the very sorts of intentions, expectations, and attitudes that make such relationships more intimate and personal.

An opponent might double down and maintain that this 'thin' notion of a relationship enabling the account to accommodate impersonal blame is not doing any real theoretical work. Why not simply understand such cases in terms of violations of moral obligations or norms? One answer, I think, comes down to the issue at the heart of this paper. If we are to understand the Sunday morning paper reader's response as a genuine blame response, then it must consist of something beyond a judgement that the murderer has culpably violated some moral norm. The blamer must be engaged by such a judgment in some way. Now, as we have seen, there are different ways of attempting to account for that engagement. But by understanding the Sunday morning paper reader's response in terms of a judgment that the murderer has done something that has some significance for him—-for example, insofar as they are fellow rational beings capable of showing concern for the moral justifiability of their actions and attitudes — and a modification to his attitudes towards that person accordingly, we can begin to get some fruitful traction on the kind of engagement that is characteristic of blame. And this is all I really have in 
mind when I connect blame to relationships. Moreover, by emphasizing, as I have earlier, that there are of course different kinds of relationships, we can get traction on the difference between the degree or kind of engagement that is characteristic of different kinds of blame.

All of this said, I am really only committed to defending my epistemic extension of the relationship-based framework. And, much like the "leaves the blame out of blame" objection from Section 5.1, the present worry strikes me as less weighty when it comes to my epistemic extension. ${ }^{27}$ Developing a full account of the differences between impersonal and personal blame in the epistemic domain is a larger project than space allows here. But, to add to some of the remarks I made in Section 4 about the account's ability to explain different kinds of blame, I'll close with the following brief sketch. Perhaps we can in some sense appropriately epistemically blame very distant or dead epistemic agents. But these responses will plausibly be different in character in comparison with what we go in for when we blame a person with whom we stand in a closer epistemic relationship, or, in other words, whose epistemic behavior has more significance for us (for example, as the Brette case illustrates). The difference here will be mirrored precisely in the comparative significance of the modifications (or reaffirmations) we make to our intentions and expectations towards the epistemic agent in question.

\section{Conclusion}

The project of developing an account of the nature of epistemic blame is still in its infancy. Brown has done much to advance our understanding of how we might draw on existing resources in moral philosophy, and put them to work in the epistemic domain. This paper has identified a challenge for any account of the nature of epistemic blame. Namely, it must be able to explain the significance of epistemic blame-what it is that makes epistemic blame something over and above mere epistemic evaluation-without invoking practices or behaviors that seem out of place in the epistemic domain. Drawing on an insight from Smith, I have argued that Brown's account ultimately falls short of meeting this challenge. However, I have argued that it falls short 
instructively. I agree with Brown that epistemic blame necessarily comes with a motivational component. But I hope to have shown that that motivational component should not be understood in terms of a desire that the target of blame not have believed badly. Couching our understanding of epistemic blame in terms of such a desire prevents us from being able to explain the significance of epistemic blame. However, we can account for the motivational component of epistemic blame in other ways. I have argued that one illuminating option is to understand it in terms of modifications to the intentions and expectations that comprise our epistemic relationships with one another. I have developed an account of the general epistemic relationship to illustrate the sort of thing I have in mind. The relationship-based account shares many attractive features of Brown's Sher-based account. But it can also explain the significance of epistemic blame, without invoking practices or behaviors that seem out of place in the epistemic domain.

\section{References}

Bartolotti, L. \& Miyazono, K. 2015. The ethics of delusional belief. Erkenntnis, 81: 275-296.

Bell, M. 2013. The standing to blame: a critique. In Blame: Its Nature and Norms, Coates, D.J \& Tognazzini, N.A (eds.). OUP: Oxford.

Boult, C. 2020. There is a distinctively epistemic kind of blame. Philosophy and

Phenomenological Research. Online first. 2019. Excuses, exemptions, and derivative norms. Ratio, 32: 150-158. 2017a. Epistemic normativity and the justification-excuse distinction. Synthese, 194: 4065-4081. 2017b. Knowledge and attributability. Pacific Philosophical Quarterly, 98:329-50.

Brown, J. 2020. What is epistemic blame? Noûs, 54: 389-407.

2017. Blame and wrongdoing. Episteme, 14:3.

Kauppinen, A. 2018. Epistemic norms and epistemic accountability. Philosophers' Imprint. 
McCraw, B. 2015. The nature of epistemic trust. Social Epistemology 29: 413-430.

McHugh, C. 2012. Epistemic deontology and voluntariness. Erkenntnis 77.

Menges, L. 2017. The emotion account of blame. Philosophical Studies 174.

Nottelmann, N. 2007. Blameworthy Belief: A Study in Epistemic Deontologism. Springer:

Dordrecht.

Radzik, L. 2012. On the virtue of minding our own business. Journal of Value Inquiry, 46:2.

2011. On minding your own business: differentiating accountability relations

within the moral community. Social Theory and Practice, 37:4.

Rettler, L. 2017. In defense of doxastic blame. Synthese, online first.

Russel, B. 2001. Epistemic and moral duty. In Steup, M. (ed.) Knowledge, Truth, and Duty.

Essays on Epistemic Justification, Responsibility, and Virtue, OUP: Oxford.

Scanlon, T.M.1998. What We Owe to Each Other. Harvard University Press: Cambridge.

2008. Moral dimensions: Permissibility, Meaning, Blame. Belknap Press:

Cambridge, MA.

Sher, G. 2006. In Praise of Blame, OUP: Oxford.

Smith, A. 2013. Moral blame and moral protest. In Blame: Its Nature and Norms, Coates, D.J \& Tognazzini, N.A (eds.). OUP: Oxford.

Strawson, P. 1962. Freedom and resentment. In Proceedings of the British Academy, Vol. 48:

1962, G. Watson (ed.). OUP: Oxford.

Todd, P. 2017. A unified account of standing to blame. Noûs, 347-374.

Wallace, R.J. 1994. Responsibility and the Moral Sentiments. Harvard University Press.

2013. Dispassionate oppribrium. In Blame: Its Nature and Norms, Coates, D.J \&

Tognazzini, N.A (eds.). OUP: Oxord.

Wolf, S. 2011. Blame, Italian style. In Reasons and Recognition. 
${ }^{1}$ Not everyone agrees that there is a distinctively epistemic kind of blame. This paper assumes that there is such thing as epistemic blame and examines the prospects of accounting for it in different ways.

${ }^{2}$ Widely discussed conditions on standing to blame include a non-complicity condition (Bell 2013), a business condition (Radzick 2011, 2012; cf. Todd 2017), a non-hypocrisy condition (Bell 2013), among others (Todd 2017).

${ }^{3}$ This approach to moral blame is not without defenders. See Wallace (2011) and Menges (2017) for very different defenses.

${ }^{4}$ Some may disagree and think negative emotional responses such as indignation and resentment are perfectly legitimate responses to people for their epistemic failings. The account of epistemic blame I develop below can accommodate this view.

${ }^{5}$ In Boult 2020, I discuss this alternative framework in the context of defending the very idea that there is a distinctively epistemic kind of blame.

${ }^{6}$ The account does not require that ordinary speakers have the explicit concept of an "epistemic norm violation." Rather, the contents of blame's belief-desire pair can be more specific: they can concern failures to conform belief to the evidence, assertions of falsehoods, etc.

${ }^{7}$ For detailed discussion of culpable versus non-culpable epistemic norm violation, see Boult 2019, 2017a, $2017 \mathrm{~b}$.

${ }^{8}$ Here is one possible case. Tim and Bob are old roommates; they compete over just about everything. One of Bob's character flaws is that he is a sucker for tabloids. He tends to believe things about celebrities and current events simply on the basis of his favorite tabloid magazine. Tim has just realized that Bob has formed yet another tabloid-based belief. Tim believes that an epistemic norm has been violated (e.g. the rational credibility norm of belief, or the knowledge norm, etc.). He also manifests many of the dispositions to feel and behave that Brown says are typically associated with epistemic blame- he publicly expresses rebuke, and attempts to get Bob to appreciate the reasons he seems to fail to appreciate. But, out of a sense of rivalry, Tim also takes a twisted pleasure in Bob's tabloid problem. He takes pleasure in Bob's formation of a shoddy tabloid-based belief. It seems Tim lacks a desire that the epistemic norm not be violated. After all, he takes pleasure in the fact that an epistemic norm has been violated. It also seems Tim epistemically blames the Bob. After all, he believes Bob has violated an epistemic norm, and manifests a range of dispositions Brown claims are typical of epistemic blame.

${ }^{9} \mathrm{I}$ am also suspicious of the need to posit weak or overridden desires as a way dealing with cases in which the relevant desire does not seem present. However, I will remain neutral on that issue.

${ }^{10}$ Sher addresses something close to the concern I am raising here in Sher (2006, 112-13). In particular, he argues that he is not claiming that for every person imaginable, the belief-desire pair at the heart of blame will give rise to the dispositions characteristic of blame in all situations. He argues that he does not need such a commitment in order for his account to work. Rather, according to Sher, it merely needs to be the case that for all cases of people with a "standard" (p.112) psychology, the belief-desire pair will tend to give rise to the dispositions characteristic of blame. This is why I have emphasized that the mother-son case 
is not an unusual case. Doing so, I explicitly distinguish it from the sort of thing Sher considers in the neighborhood: namely, "imaginary" or "far off" cases in which a person has the belief-desire pair, but not the dispositions. My aim here is to point out that the mother-son case seems like a normal sort of case. ${ }^{11}$ Here is a more detailed worry about the explanatory connections Sher himself spells out. According to Sher, the connection between blame's belief-desire pair and dispositions to reproach and apologize (two dispositions he claims are characteristic of blame) is an instance of a general kind: the connection between desire frustration and getting the next best thing. By reproaching, roughly speaking, we aim to get others to avoid wrongdoing in the future, or to try and be better people in the future. By apologizing for a moral transgression, roughly speaking, we aim to get others to see that we have the relevant desire that we not have done so. Interestingly, by Sher's own (plausible) lights, it seems this story about reproach can't be quite right. Sher himself rejects consequentialist theories of blame, for reasons that seem applicable here. In particular, it seems A can blame B, reproaching B, while nevertheless lacking any expectation (or even desire) whatsoever that B will behave differently in the future. Perhaps A simply writes B off, or even wants B to continue failing for some overriding consequential reason. Concerning apology, this strikes me as a strange explanation of why we apologize. Namely, it seems like the wrong kind of reason to apologize to someone. In particular, it seems selfish and self-centered to apologize to someone so that they see you have desire X about morality. A good apology is, perhaps among other things, one that is done because you care about the person you're apologizing to - because you want them to be better off, which might of course be brought about through letting them know you care. But the former, not the latter, is the primary motivation behind a good apology. On Sher's theory, it seems the latter is the content of your desire. So, by drawing the particular connections he does between frustrated desires and apologies, Sher may be forced to license bad apologies. Below I discuss whether there might be some parallel worries for Brown when it comes to reproach.

${ }^{12}$ This isn't to say that the son may not have failed in other ways besides epistemically.

${ }^{13}$ If these specific emotions seem somewhat out of place, replace them with something less extreme, or assume that the exam is a particularly important one.

${ }^{14}$ Brown draws connections between epistemic blame's belief-desire pair and characteristic dispositions in a way that parallels Sher. According to Brown, if someone experiences "negative feelings such as anger" towards another for their epistemic failing, this can be explained as the manifestation of a typical disposition towards such feelings when one of our desires is frustrated. If someone reproaches another-for example, through verbal expressions such as "How can you believe the president is in New York given that the TV is showing that he is in Washington?!'(Brown 2020,11) — this can be explained as the manifestation of a disposition to try to achieve the next best thing to an unachievable goal (in this case, that the person not have believed badly), namely, to get them to appreciate the epistemic reasons they have and perhaps conduct their intellectual lives more carefully in the future. It is thus worth pointing out that Brown's epistemic extension seems to inherit a parallel worry to the one I canvassed above for Sher: it seems we can epistemically blame others without any hope or desire that they appreciate anything, or do 
anything differently in future (even if it is true that we do desire that they not have believed badly). Perhaps we've simply written them off. Since I am ultimately concerned with a bigger picture worry for the general account in both its epistemic and moral varieties, I will leave these matters to one side for now.

${ }^{15}$ It is worth noting that Brown responds to Smith's mother-son case in Brown (2020). However, I am not convinced that her response addresses the heart of the problem. Brown interprets the objection as a straightforward counterexample in which all of the conditions of the Sher-based account of blame are supposedly satisfied and yet intuitively there is no blame. Interpreted as such, I agree with Brown that the objection clearly misses the mark; after all, the dispositions characteristic of blame (a condition on blame, according to the account) are missing. However, in my view, this feature of the case is precisely the point. As I have presented it — and I'll leave it open whether my objection here is ultimately the same as Smith's or simply a new objection - the case is not intended to be a case in which all of the conditions of the Sherbased account of blame are satisfied and yet intuitively there is no blame. Rather, it is meant to be an illustration of how, under very normal circumstances, a person can have the belief-desire pair involved in the Sher-based account of blame without this giving rise to the sorts of dispositions that are characteristic of blame. Again, a central feature of the Sher-based account is that the dispositions characteristic of blame just are a special case of what people do when their desires are frustrated. This is supposed to be part of the explanatory power of the account. The belief-desire pair is supposed to explain why the reactions characteristic of blame are ones we would expect people to have under the relevant circumstances. I hope to have more explicitly brought out the challenge to this explanatory claim of the account.

${ }^{16}$ For a deployment of this idea in the context of responding to skepticism about whether there is a distinctively epistemic kind of blame, see Boult 2020.

${ }^{17}$ Strictly speaking, relationships also consist in actual dispositions people have towards each other (in addition to their intentions, for example), as well as the reasons why they have those intentions and dispositions. I will bracket these additional two points for the sake of presenting the basic idea of the account.

${ }^{18}$ The account does not require that ordinary speakers have the concept of an "epistemic relationship", or the concept of an impairment of such a relationship. Rather, the contents of any blame-relevant judgment can be more specific: they can concern failures to conform belief to the evidence, assertions of falsehoods, etc. These are things that, we will see below, constitute impairments of different sorts of epistemic relationships.

${ }^{19}$ Note that this way of developing the idea of an epistemic relationship does not commit one to "antireductionism" in the testimonial justification debate (Greco 2015). Both anti-reductionists and reductionists about testimonial justification can agree that, unless we have good reason not to, we should epistemically trust the word of other epistemic agents. Anti-reductionists can agree, because they maintain that testimony is a sui generis source of justification. Reductionists can agree, because they maintain that we often possess other sources of justification (abductive inference, knowledge of track records, etc.) in support of epistemically trusting the word of others. 
${ }^{20}$ This feature of my account overlaps in interesting ways with recent work by Kauppinen (2018). Kauppinen puts "reductions in epistemic trust" to work in a theory of "epistemic accountability". Interestingly, he denies that there is such thing as epistemic blame.

${ }^{21}$ Thanks to an anonymous referee for pressing this point.

${ }^{22}$ Different descriptions of normative ideals of other kinds of epistemic relationships will afford equally fine-grained explanations of other forms of epistemic blame, should they exist.

${ }^{23}$ For those who are sympathetic to negative emotional response accounts of blame, it is important to remember that we can allow that certain kinds of emotion will normally accompany blame-responses.

${ }^{24}$ Thanks to Adam Piovarchy for helpful discussion, and suggesting this possibility of higher-order intentions and expectations. Scanlon himself anticipates this sort of worry and responds by simply allowing the notion of reaffirmation of intentions and expectations to play a role in his account $(2008,131)$.

${ }^{25}$ See Menges for helpful discussion of the difference between "emotion stances" and "emotion episodes" in the context of a defense of a Strawsonian approach to the nature of blame.

${ }^{26}$ Thanks to an anonymous referee for pressing this point.

${ }^{27}$ Perhaps this is because I am more confident readers will share my intuition that our epistemic blame responses towards very distant or dead people — if we ever appropriately have them — are different in kind from our epistemic blame responses towards people who occupy some more significant role in the epistemic relationship. 